\title{
Indications for Emergency Abdominal Surgeries in Older Patients: 7-Year Experience of a Single Centre
}

\author{
Weronika Lebowa $^{1} \cdot$ Urszula Skorus $^{1} \cdot$ Kamil Rapacz $^{1} \cdot$ Jakub Kenig $^{1}$ (D) \\ Received: 11 July 2019 / Accepted: 9 April 2020 / Published online: 24 April 2020 \\ (C) The Author(s) 2020
}

\begin{abstract}
The majority of patients undergoing emergency laparotomy are older adults that carry the highest mortality. More research into the development of targeted interventions is required. Therefore, the aim of the study was to analyse the indications for emergency abdominal surgery in patients aged $\geq 65$ admitted to the Department of General Surgery. The study included consecutive patients aged $\geq 65$ who underwent emergency abdominal surgery within $48 \mathrm{~h}$ after admission at one institution. In 2010-2017, 986 patients were enrolled in the study (female $57 \%$, male $43 \%$ ). Patients were divided into three age groups, 65-70, 71-84 and $\geq 85$, with 255 patients (25.9\%), 562 patients $(57.0 \%)$ and 169 patients (17.1\%) in each group, respectively. In the first and second age groups, the most common indications for surgery were acute cholecystitis, non-malignant ileus, colorectal cancer complications and acute appendicitis. In the oldest patients, the most common indications were complications of colorectal cancer, acute cholecystitis, nonmalignant ileus and complications of diverticulosis. In the women, the biggest differences in indications between age groups were colorectal cancer $(p=0.025)$ and peptic ulcer disease complications $(p=0.005)$; in the men, the biggest difference was seen for complicated diverticulitis $(p=0.001)$. The most frequent comorbidities were heart diseases $(81.0 \%)$, followed by endocrine $(33.6 \%)$ and vascular diseases $(22.7 \%)$. The three most common indications for emergency surgery in older patients at our institution were acute cholecystitis, colorectal cancer complications and non-malignant bowel obstruction, affecting $59.5 \%$ of this group of patients. Elective surgery and endoscopic screening have the potential to prevent major part of these acute diseases. However, further prospective research is necessary on this field, particularly among frail, older patients.
\end{abstract}

Keywords Acute abdomen $\cdot$ Abdominal surgery $\cdot$ Emergency surgery $\cdot$ Geriatric patients $\cdot$ Older patients

\section{Introduction}

A general improvement in living conditions and healthcare quality has led to global increases in average life expectancy, with an associated increase in the elderly population [1]. According to the available literature, patients $\geq 65$ years make up $15-21 \%$ of patients admitted to the Emergency Department (ED), and rising $[2,3]$. While $10 \%$ of all consultations in the ED are caused by abdominal pain, 20-25\% of these are geriatric patients, $22 \%$ of whom require emergency surgery $[4,5]$. In the elderly population, several factors hamper the diagnostic process and delay implementation of appropriate treatment,

Jakub Kenig

jkenig@cm-uj.krakow.pl

1 Department of General Oncologic and Geriatric Surgery, Jagiellonian University Medical College, 35-37 Pradnicka str, 31-202 Krakow, Poland including difficulties in gathering relevant past medical history, atypical presentation of clinical symptoms and presence of comorbidities. Importantly, an early decision for surgery, when necessary, is one of the most important prognostic factors [3, 5-8]. Diagnostic delays and suboptimal treatment lead to a high percentage of postoperative complications (exceeding 50\%) and a high in-hospital mortality rate (11-37\%) [9-11]. The literature evaluating the indication for emergency surgery in larger population of older, consecutive patients is scarce. Therefore, the aim of this study was to analyse indications for emergency abdominal surgeries among consecutive patients aged $\geq 65$ admitted to the Department of General Surgery.

\section{Methods}

The study sample comprised of consecutive patients aged $\geq 65$ who underwent emergency abdominal surgery within $48 \mathrm{~h}$ 
after admission to the Department of Surgery. Data from 2010 to 2011 were obtained retrospectively from medical records and perioperative reports. Other information, in 2012-2017, was collected prospectively. The Ethics Committee of the Jagiellonian University approved the study.

Emergency surgical conditions were classified into the following 12 categories: acute cholecystitis, colorectal cancer complications (bowel obstruction, bleeding, perforation), non-malignant obstruction (strangulated hernia, volvulus, adhesion, gallstone ileus), acute appendicitis, complicated diverticulitis (perforation, bleeding requiring surgical intervention), peptic ulcer disease complications (perforation, bleeding requiring surgical intervention), acute intestinal ischemia, pancreatic cancer complications (biliary obstruction, bowel obstruction), gastric cancer complications (perforation, pylorus obstruction, bleeding), peritoneal carcinomatosis, other malignant (retroperitoneal sarcoma, ovarian or bladder cancer causing bowel obstruction) and other non-malignant (trauma/intraabdominal abscesses requiring surgical intervention).

Included patients were divided into the following three age groups: $65-70,71-84$ and $\geq 85$. Patients were also divided into two groups according to gender. Patients not requiring laparoscopy or laparotomy (undergoing minor procedures) were excluded from the analysis.

\section{Statistical Analysis}

Statistical analysis was performed using STATISTICA StatSoft ${ }^{\circledR} 13.0$ software. Frequencies $(n)$ with percentages (\%) are given for qualitative variables. The Shapiro-Wilk test was used to confirm the normality of the distribution of quantitative variables. Medians were used to describe the central tendency of the quantitative variables, and the minimum and maximum values were given. Pearson's chi-squared test was used to compare nominal variables. The results were considered statistically significant for $p<0.05$.

\section{Results}

In 2010-2017, we enrolled 986 patients aged 65 or more who underwent emergency abdominal surgery. We identified 255 (25.9\%), $562(57.0 \%)$ and $169(17.1 \%)$ patients in the 65-70, $71-84$ and $\geq 85$ age groups, respectively, and the median age was $76(65-102)$. There were 562 women (57\%) and 424 men $(43 \%)$. There were significantly more women and significant differences in all the age groups $(p=0.004)$. The demographic data for individual age groups of patients are presented in Table 1.

Table 1 also presents a detailed analysis of surgical indications. The most common indications were acute cholecystitis (24.3\%), colorectal cancer complications (17.9\%) and nonmalignant bowel obstruction (17.3\%).
Acute cholecystitis was the most common cause of hospitalisation in the both $65-70(25.1 \%)$ and $71-84$ (25.8\%) age groups. In the oldest patients $(\geq 85)$, the most frequent indication was colorectal cancer complications. In the first two age groups, the four most common indications were identical: acute cholecystitis, non-malignant bowel obstruction, complications of colorectal cancer and acute appendicitis. In the oldest patients $(\geq 85)$, the order of the most common indication was different: colorectal cancer complications, acute cholecystitis, non-malignant obstruction and complicated diverticulitis.

The frequencies of particular diseases differed significantly between the age groups. Acute appendicitis represented $14.9 \%$ of all diagnoses among the youngest patients, while in patients aged $71-84$ and $\geq 85$, it was $7.3 \%$ and $5.9 \%$, respectively $(p=0.001)$. Colorectal cancer complications were the most frequent in the group of the oldest patients at $24.3 \%$, while in patients aged 71-84 and 65-70, it represented $17.3 \%$ and $14.9 \%$, respectively $(p=0.041)$. Diverticulosis complications in the first, second and third age groups were reported with frequencies of $3.1 \%, 6.4 \%$ and $9.5 \%$, respectively $(p=$ 0.025). Complications of peptic ulcer disease were $2.8 \%$, $6.4 \%$ and $8.9 \%$, respectively $(p=0.023)$. Table 2 and Figs. 1 and 2 present analysis of subgroups based on gender.

In the women, the most common indications for emergency surgery were acute cholecystitis (22.4\%), non-malignant bowel obstruction $(20.5 \%)$ and colorectal cancer complications $(15.5 \%)$. Acute cholecystitis was the most common diagnosis in patients aged $65-70(21.6 \%)$ and in 71-84 (25.9\%). However, among the oldest patients, acute cholecystitis was only the third most frequent reason for hospitalisation (13.9\%) $(p=0.030)$. The incidence of colon cancer complications increased among women with age, in subsequent age groups $11.9 \%, 14.1 \%$ and $23.5 \%$ (the most frequent reason for hospitalisation in the patients aged $\geq 85)(p=0.025)$. The same tendency was observed for the diagnosis of peptic ulcer disease complications, $2.2 \%, 5.8 \%$ and $12.2 \%$, respectively $(p=0.005)$. Diagnosis of acute appendicitis in consecutive age groups had a decreasing share in the total number of diagnoses, $17.2 \%, 8.0 \%$ and $3.5 \%$, respectively $(p=0.001)$.

In the men, the most common indications for emergency surgery were acute cholecystitis $(26.9 \%)$, colorectal cancer complications (21.0\%) and non-malignant bowel obstruction (13.2\%). In the 65-70 and 71-84 age groups, the most common indications did not differ significantly. Only in case of complicated diverticulitis, the prevalence increased significantly with age, with patients aged $\geq 85$ having a significantly higher prevalence $1.7 \%, 2.8 \%$ and $13.0 \%$, respectively $(p=$ 0.001).

Table 3 presents the prevalence of the comorbidities in the study population. In heart diseases (history of myocardial infarction, ischemic heart disease, chronic heart failure, valvular heart disease) $81.0 \%$ was the most common comorbidity, 
Table 1 Demographic data and indication for emergency surgery in the elderly patients

\begin{tabular}{llllll}
\hline & All patients & Age group & & \multirow{2}{*}{$p$ value } \\
\cline { 3 - 5 } & & $65-70$ & $71-84$ & $\geq 85$ & - \\
\hline Number of patients (\%) & 986 & $255(25.9)$ & $562(57.0)$ & $169(17.1)$ & - \\
Women (\%) & $562(57.0)$ & $134(23.8)$ & $313(55.7)$ & $115(20.5)$ & $\mathbf{0 . 0 0 4}$ \\
Men (\%) & $424(43.0)$ & $121(28.6)$ & $249(58.7)$ & $54(12.7)$ & \\
Median age (range) & $76(65-102)$ & $67(65-70)$ & $77(71-84)$ & $88(85-102)$ & - \\
Indications for surgery & & & & & \\
Acute cholecystitis & $240(24.3 \%)$ & $64(25.1 \%)$ & $145(25.8 \%)$ & $31(18.3 \%)$ & 0.133 \\
Colorectal cancer complications & $176(17.9 \%)$ & $38(14.9 \%)$ & $97(17.2 \%)$ & $41(24.3 \%)$ & $\mathbf{0 . 0 4 1}$ \\
Non-malignant bowel obstruction & $171(17.3 \%)$ & $43(16.9 \%)$ & $97(17.3 \%)$ & $31(18.3 \%)$ & 0.922 \\
Acute appendicitis & $89(9.0 \%)$ & $38(14.9 \%)$ & $41(7.3 \%)$ & $10(5.9 \%)$ & $\mathbf{0 . 0 0 1}$ \\
Diverticulosis complications & $60(6.1 \%)$ & $8(3.1 \%)$ & $36(6.4 \%)$ & $16(9.5 \%)$ & $\mathbf{0 . 0 2 5}$ \\
Peptic ulcer disease complications & $58(5.9 \%)$ & $7(2.8 \%)$ & $36(6.4 \%)$ & $15(8.9 \%)$ & $\mathbf{0 . 0 2 3}$ \\
Other non-malignant & $57(5.8 \%)$ & $12(4.7 \%)$ & $39(6.9 \%)$ & $6(3.6 \%)$ & 0.176 \\
Acute intestinal ischemia & $35(3.6 \%)$ & $6(2.4 \%)$ & $22(3.9 \%)$ & $7(4.1 \%)$ & 0.482 \\
Other malignant & $33(3.4 \%)$ & $16(6.3 \%)$ & $15(2.7 \%)$ & $2(1.2 \%)$ & $\mathbf{0 . 0 0 7}$ \\
Pancreatic cancer complications & $27(2.7 \%)$ & $10(3.9 \%)$ & $14(2.5 \%)$ & $3(1.8 \%)$ & 0.357 \\
Gastric cancer complications & $21(2.1 \%)$ & $8(3.1 \%)$ & $10(1.8 \%)$ & $3(1.8 \%)$ & 0.433 \\
Peritoneal carcinomatosis & $19(1.9 \%)$ & $5(2.0 \%)$ & $10(1.8 \%)$ & $4(2.4 \%)$ & 0.887 \\
\hline
\end{tabular}

*\#Other non-malignant (trauma/intra-abdominal abscesses requiring surgical intervention), other malignant (retroperitoneal sarcoma, ovarian or bladder cancer causing ileus) followed by the endocrine diseases (diabetes mellitus, hyperthyroidism, hypothyroidism), 33.6\%, vascular diseases (history of cerebrovascular accident, peripheral arterial disease, intermittent claudication, aortic aneurysm), $22.7 \%$, gastrological diseases (active peptic ulcer disease, chronic hepatitis), 18.8\%, neurologic diseases (hemiplegia, epilepsy, multiple sclerosis, neuromuscular diseases or neurodegenerative disorders), $17.1 \%$ and psychiatric diseases (dementia, depression, psychotic, bipolar or anxiety disorders), $6.2 \%$. Significant differences in age groups were observed for heart diseases and neurologic diseases. The prevalence increased with age, $64.9 \%, 84.2 \%, 88.2 \%$ for heart diseases $(p<$ $0.001)$ and $12.6 \%, 17.1 \%, 24.3 \%$ for neurological disorders ( $p=0.007)$, respectively. Concerning gender, endocrine comorbidities were observed more frequent among females than males, $37 \%$ vs. $29 \%, p=0.008$.

\section{Discussion}

The elderly population is growing both in Poland and throughout Europe. Today, people aged $\geq 65$ constitutes $15 \%$ of the European population [12]. This is reflected in the slowly rising average age, which is currently 41.9 in Europe and 29.2 globally [13]. Due in part to rising life expectancies, the number of older patients admitted to hospitals is also increasing.

The literature confirms our observation that more women are admitted to the hospital than men $[3,6,7,14]$. Fenyö et al. have shown that females accounted for almost two thirds of patients with an acute abdomen [9]. In our study, the percentage was $57 \%$ and the difference was statistically significant. Only Huang et al reported a higher percentage of males among older patients [15]. Previous studies have shown that the male-female ratio decreases with age, probably reflecting women's longer life expectancy [14].

Authors analysing surgical indications in the elderly admitted to the emergency department have identified the most common causes of acute abdominal pain to be gallbladder disease and biliary tract disorders $[3-6,8,16]$. We found the three most common indications for surgery in patients $\geq 65$ to be acute cholecystitis, colorectal cancer complications and non-malignant bowel obstruction, representing $59.5 \%$ of all patients. Minor differences in results between studies may be derived from the application of different inclusion criteria and the different characteristics of research populations [3-5].

Laurell et al. and Rosenthal et al. showed that acute cholecystitis was the most common cause of acute abdomen in elderly patients $(\geq 65)$, which is consistent with our results $[7,17]$. Generally, the incidence of cholelithiasis increases with age, reaching 33\% among people aged 70 [18]. Factors predisposing gallstone formation include altered bile acid production, high cholesterol bile saturation and reduced gallbladder sensitivity to cholecystokinin. Moreover, no gender differences in incidence were seen (female $22.4 \%$ vs. male $26.9 \%$ ), not the case in younger patients [18]. However, importantly, acute cholecystitis can be prevented in this population by 
Table 2 Indications for emergency surgery in female and male older patients (analysis in the three age groups)

\begin{tabular}{|c|c|c|c|c|c|}
\hline & \multirow{2}{*}{$\begin{array}{l}\text { Female } \\
\text { Male }\end{array}$} & \multicolumn{3}{|l|}{ Age } & \multirow[t]{2}{*}{$p$ value } \\
\hline & & $65-70$ & $71-84$ & $\geq 85$ & \\
\hline \multirow[t]{2}{*}{ Acute cholecystitis } & $126(22.4 \%)$ & $29(21.6 \%)$ & $81(25.9 \%)$ & $16(13.9 \%)$ & 0.030 \\
\hline & $114(26.9 \%)$ & $35(28.9 \%)$ & $64(25.7 \%)$ & $15(27.8 \%)$ & 0.796 \\
\hline \multirow[t]{2}{*}{ Non-malignant bowel obstruction } & $115(20.5 \%)$ & $28(20.9 \%)$ & $61(19.5 \%)$ & $26(22.6 \%)$ & 0.770 \\
\hline & $56(13.2 \%)$ & $15(12.4 \%)$ & $36(14.5 \%)$ & $5(9.3 \%)$ & 0.565 \\
\hline \multirow[t]{2}{*}{ Colorectal cancer complications } & $87(15.5 \%)$ & $16(11.9 \%)$ & $44(14.1 \%)$ & $27(23.5 \%)$ & 0.025 \\
\hline & $89(21.0 \%)$ & $22(18.2 \%)$ & $53(21.3 \%)$ & $14(26.0 \%)$ & 0.501 \\
\hline \multirow[t]{2}{*}{ Acute appendicitis } & $52(9.25 \%)$ & $23(17.2 \%)$ & $25(8.0 \%)$ & $4(3.5 \%)$ & 0.001 \\
\hline & $37(8.7 \%)$ & $15(12.4 \%)$ & $16(6.4 \%)$ & $6(11.1 \%)$ & 0.130 \\
\hline \multirow[t]{2}{*}{ Complicated diverticulitis } & $44(7.8 \%)$ & $6(4.5 \%)$ & $29(9.3 \%)$ & $9(7.8 \%)$ & 0.225 \\
\hline & $16(3.8 \%)$ & $2(1.7 \%)$ & $7(2.8 \%)$ & $7(13.0 \%)$ & 0.001 \\
\hline \multirow[t]{2}{*}{ Peptic ulcer disease complications } & $35(6.2 \%)$ & $3(2.2 \%)$ & $18(5.8 \%)$ & $14(12.2 \%)$ & 0.005 \\
\hline & $23(5.4 \%)$ & $4(3.3 \%)$ & $18(7.2 \%)$ & $1(1.9 \%)$ & 0.137 \\
\hline \multirow[t]{2}{*}{ Other non-malignant ${ }^{*}$} & $28(5.0 \%)$ & $6(4.5 \%)$ & $18(5.8 \%)$ & $4(3.5 \%)$ & 0.603 \\
\hline & $29(6.8 \%)$ & $6(5.0 \%)$ & $21(8.4 \%)$ & $2(3.7 \%)$ & 0.287 \\
\hline \multirow[t]{2}{*}{ Acute intestinal ischemia } & $22(3.9 \%)$ & $3(2.2 \%)$ & $14(4.5 \%)$ & $5(4.4 \%)$ & 0.518 \\
\hline & $13(3.1 \%)$ & $3(2.5 \%)$ & $8(3.2 \%)$ & $2(3.7 \%)$ & 0.890 \\
\hline \multirow[t]{2}{*}{ Other malignant ${ }^{\#}$} & $20(3.6 \%)$ & $11(8.2 \%)$ & $7(2.2 \%)$ & $2(1.7 \%)$ & 0.004 \\
\hline & $13(3.1 \%)$ & $5(4.1 \%)$ & $8(3.2 \%)$ & $0(0.0 \%)$ & 0.335 \\
\hline \multirow[t]{2}{*}{ Peritoneal carcinomatosis } & $14(2.5 \%)$ & $4(3.0 \%)$ & $6(1.9 \%)$ & $4(3.5 \%)$ & 0.600 \\
\hline & $5(1.2 \%)$ & $1(0.8 \%)$ & $4(1.6 \%)$ & $0(0.0 \%)$ & 0.559 \\
\hline \multirow[t]{2}{*}{ Pancreatic cancer complications } & $13(2.3 \%)$ & $3(2.2 \%)$ & $8(2.6 \%)$ & $2(1.7 \%)$ & 0.881 \\
\hline & $14(3.3 \%)$ & $7(5.8 \%)$ & $6(2.4 \%)$ & $1(1.9 \%)$ & 0.191 \\
\hline \multirow[t]{2}{*}{ Gastric cancer complications } & $6(1.1 \%)$ & $2(1.5 \%)$ & $2(0.6 \%)$ & $2(1.7 \%)$ & 0.531 \\
\hline & $15(3.5 \%)$ & $6(5.0 \%)$ & $8(3.2 \%)$ & $1(1.9 \%)$ & 0.537 \\
\hline
\end{tabular}

Bold values denote statistical significance at the $p<0.05$ level

*\#other non-malignant (trauma/intra-abdominal abscesses requiring surgical intervention/necrotic acute pancreatitis/ diagnostic laparotomy), other malignant (retroperitoneal sarcoma, ovarian or bladder cancer causing ileus) elective surgery. Many surgeons hesitate to operate on older patients with symptomatic cholelithiasis. However, we have shown in our previous study that elective laparoscopic cholecystectomy, in experienced hands, is safe, even in frail older patients, and can be performed with minor morbidity and no mortality [19].
The second and third most common indication for acute surgery were colorectal cancer complications (consisting mostly of tumour induced bowel obstruction) and nonmalignant bowel obstruction due to hernia strangulation and volvulus and adhesions. Causes of small intestinal obstruction differ between young and older patients. Typically, younger
Fig. 1 Prevalence of selected diseases indicated for emergency abdominal surgery in women (analysis of three age groups)




Fig. 2 Prevalence of selected indications for emergency abdominal surgery in men (analysis of three age groups)

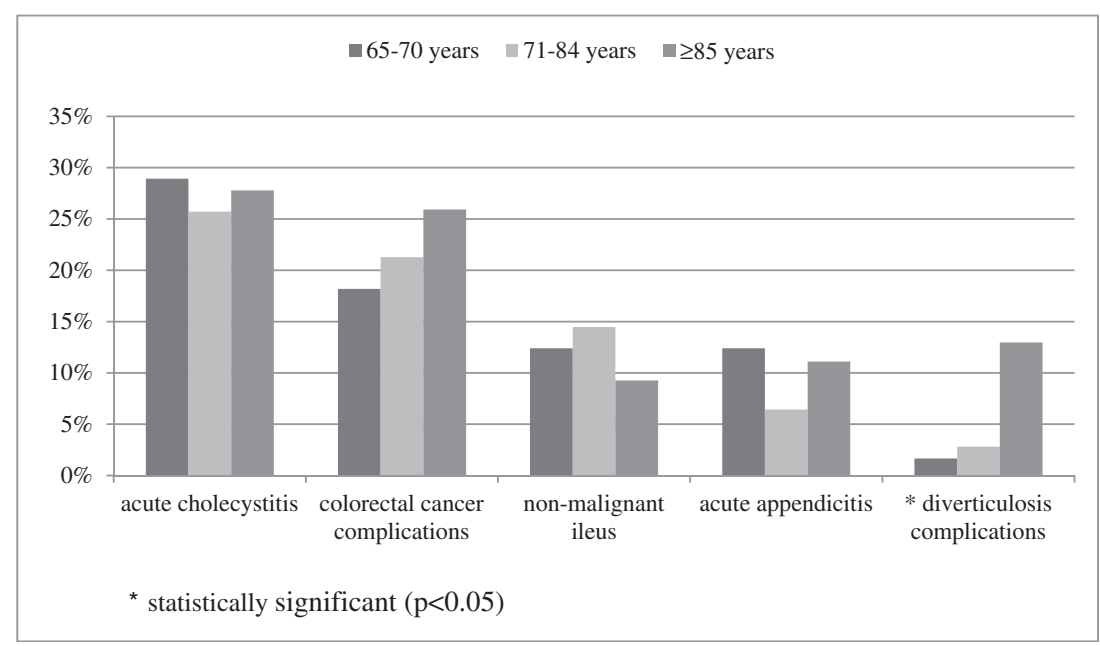

patients are more likely to have symptomatic adhesions, whereas both groups experience strangulated hernia and volvulus. Meanwhile, colorectal cancer, diverticulitis and volvulus are primarily responsible for large intestinal obstruction and are diagnosed mostly in older individuals [20]. It should be noted that these causes are preventable by regular colonoscopic screening and elective hernia surgery.

In the general population, acute appendicitis is the most common indication for emergency abdominal surgery, and the third most common in the elderly [21]. In our population, acute appendicitis was the fourth most common reason for surgery. With increased age, we observed decreasing percentages of patients undergoing surgery due to appendicitis. However, attention should be paid to the general increase in appendicitis incidence in the elderly [21].

Age correlates positively with diverticulitis incidence. Eighty per cent of people over 85 have diverticulosis. It is estimated that at some point in their lives, about $20 \%$ of them will experience diverticulitis and another $20 \%$ suffer from complications [22]. Our study found that in the oldest individuals $(\geq 85)$ diverticulosis complications led to emergency abdominal surgery more often than in younger geriatric patients.
Peptic ulcer disease is a disorder often underdiagnosed among older people. In about half of patients over 60 , the first symptom of peptic ulcer disease is a life-threatening complication, most often gastrointestinal perforation [23]. In our research, this was the sixth most common indication for emergency abdominal surgery. We also observed that its occurrence was significantly higher in older patients. Comparing historical data with more recent reports, decreased incidence of peptic ulcer disease complications is evident, probably due to progress in pharmacotherapy and increased physician awareness. Nevertheless, it is still an important reason for acute abdomen, especially in the oldest patients.

Concerning gender, Gardner et al. found that in patients aged $>70$, there were no significant gender differences in the frequencies of several surgical diseases, although a higher postoperative mortality rate was seen in men $(p<0.001)$ [16]. Our study showed that in women, the most prominent differences between the age groups were found in the frequencies of colorectal cancer and peptic ulcer disease complications. The frequency of colorectal cancer complications increased by $2 \%$ for the $70-84$ vs. $\geq 65$ age group and by $9 \%$ for the $\geq 85$ vs. $70-84$ age groups. Peptic ulcer disease complications similarly

Table 3 Prevalence of the comorbidities in the study population

\begin{tabular}{|c|c|c|c|c|c|c|c|c|}
\hline & \multirow{2}{*}{$\begin{array}{l}\text { Overall sample }(n=986) \\
\%\end{array}$} & \multicolumn{3}{|l|}{ Age } & \multirow[t]{2}{*}{$p$ value } & \multicolumn{2}{|l|}{ Sex } & \multirow[t]{2}{*}{$p$ value } \\
\hline & & $\begin{array}{l}65-70 \\
\%\end{array}$ & $\begin{array}{l}71-84 \\
\%\end{array}$ & $\begin{array}{l}\geq 85 \\
\%\end{array}$ & & $\begin{array}{l}\text { Female } \\
\%\end{array}$ & $\begin{array}{l}\text { Male } \\
\%\end{array}$ & \\
\hline \multicolumn{9}{|l|}{ Comorbidities } \\
\hline Heart diseases & 81.0 & 69.4 & 84.2 & 88.2 & $<0.01$ & 82.8 & 78.8 & 0.12 \\
\hline Endocrine diseases & 33.6 & 31.0 & 34.2 & 35.5 & 0.57 & 37.0 & 29.0 & 0.01 \\
\hline Vascular diseases & 22.7 & 19.6 & 23.7 & 24.3 & 0.38 & 23.1 & 22.2 & 0.72 \\
\hline Gastrological diseases & 18.8 & 16.0 & 18.9 & 20.4 & 0.52 & 19.8 & 17.5 & 0.36 \\
\hline Psychiatric diseases & 6.2 & 4.31 & 6.23 & 8.88 & 0.16 & 6.6 & 5.7 & 0.55 \\
\hline Neurologic diseases & 17.1 & 12.6 & 17.1 & 24.3 & 0.01 & 15.1 & 19.8 & 0.05 \\
\hline
\end{tabular}


increased by $3.5 \%$ and $6 \%$, respectively. In men, the biggest differences between age groups were diverticulosis complications, which increased by $11 \%$ and $10 \%$, respectively.

One of the most essential factors preventing postoperative fatal outcomes is early and correct diagnosis. As it was mentioned before, in the older population, several factors hamper the diagnostic process and delay implementation of appropriate treatment, including difficulties in gathering relevant past medical history, atypical presentation of clinical symptoms and presence of comorbidities [5-8]. Therefore, obtaining computer tomography scans early can accelerate the diagnosis process and as consequence lead to improved surgical outcomes [24].

Moreover, comorbidity is common in older cancer patients and deserves special consideration. There is no consensus on how should the comorbidity burden be measured [25]. Even though many comorbidity indices were developed so far, no unified, widely used instrument exists. Patients with comorbidities have worse outcomes comparing with those with no such conditions. Although data regarding their significance is insufficient and in many cases conflicting [26, 27], not every comorbidity type may also have clinical significance, which is a topic of our ongoing study. Moreover, comorbidities cannot be optimised in the emergency setting. Therefore, acute surgeries pose a risk factor for the older patients, including significantly higher morbidity and mortality rate in comparison with the elective operations [28]. Introduction of frailty screening and other geriatric surgery concepts may be an option for further outcome improvement. However, at present, there is not enough data to draw reliable conclusion.

\section{Conclusions}

The three most common indications for emergency surgery in older patients at our institution were acute cholecystitis, colorectal cancer complications and non-malignant bowel obstruction, affecting $59.5 \%$ of this group of patients. Elective surgery and endoscopic screening have the potential to prevented great part of these acute diseases. However, further prospective research is necessary on this field, particularly among frail, older patients.

Authors' Contributions Study concepts: Weronika Lebowa, Urszula Skorus, Jakub Kenig

Study design: Weronika Lebowa, Urszula Skorus, Jakub Kenig

Data acquisition: Weronika Lebowa, Urszula Skorus, Kamil Rapacz, Jakub Kenig

Quality control of data and algorithms: Weronika Lebowa, Urszula

Skorus, Kamil Rapacz, Jakub Kenig

Data analysis and interpretation: Weronika Lebowa, Urszula Skorus, Jakub Kenig

Statistical analysis: Weronika Lebowa, Urszula Skorus

Manuscript preparation: Weronika Lebowa, Urszula Skorus, Jakub Kenig
Manuscript editing: Weronika Lebowa, Urszula Skorus, Jakub Kenig Manuscript review: Weronika Lebowa, Urszula Skorus, Jakub Kenig

\section{Compliance with Ethical Standards}

Conflict of Interest All authors of the manuscript certify that Weronika Lebowa, Urszula Skorus, Kamil Rapacz, Jakub Kenig do not have commercial associations (e.g., consultancies, stock ownership, equity interests, patent-licencing arrangements, etc.) that might pose a conflict of interest in connection with the submitted article.

Open Access This article is licensed under a Creative Commons Attribution 4.0 International License, which permits use, sharing, adaptation, distribution and reproduction in any medium or format, as long as you give appropriate credit to the original author(s) and the source, provide a link to the Creative Commons licence, and indicate if changes were made. The images or other third party material in this article are included in the article's Creative Commons licence, unless indicated otherwise in a credit line to the material. If material is not included in the article's Creative Commons licence and your intended use is not permitted by statutory regulation or exceeds the permitted use, you will need to obtain permission directly from the copyright holder. To view a copy of this licence, visit http://creativecommons.org/licenses/by/4.0/.

\section{References}

1. England K, Azzopardi-Muscat N (2017) Demographic trends and public health in Europe. Eur J Pub Health 27:9-13

2. Strange GR, Chen EH, Sanders AB (1992) Use of emergency departments by elderly patients: projections from a multicenterdata base. Ann Emerg Med 21:819-824

3. Çam PH, Baydin A, Yürüker S, Erenler AK, Șengüldür E (2018) Investigation of geriatric patients with abdominal pain admitted to emergency department. Curr Gerontol Geriatr Res 9109326

4. Fagbohun CF, Toy EC, Baker B (1996) The evaluation of acute abdominal pain in the elderly patient. Prim Care Update $\mathrm{Ob} / \mathrm{Gyns}$ 6:181-185

5. deDombal FT (1994) Acute abdominal pain in the elderly. J Clin Gastroenterol 19(4):331-335

6. Marco CA, Schoenfeld CN, Keyl PM, Menkes ED, Doehring MC (1998) Abdominal pain in geriatric emergency patients: variables associated with adverse outcomes. Acad Emerg Med 5(12):11631168

7. Laurell H, Hansson LE, Gunnarsson U (2006) Diagnostic pitfalls and accuracy of diagnosis in acute abdominal pain. Scand J Gastroenterol 41(10):1126-1131

8. Bugliosi TF, Meloy TD, Vukov LF (1990) Acute abdominal pain in the elderly. Ann Emerg Med 19:1383-1386

9. Fenyö G (1982) Acute abdominal disease in the elderly: experience from two series in Stockholm. Am J Surg 143(6):751-754

10. Cooper Z, Mitchell SL, Gorges RJ, Rosenthal RA, Lipsitz SR, Kelley AS (2015) Predictors of mortality up to one year after emergent major abdominal surgery in older adults. J Am GeriatrSoc 63(12):2572-2579

11. Reiss R, Deutsch AA (1985) Emergency abdominal procedures in patients above 70. J Gerontol 40(2):154-158

12. Bongaarts $J$ (2009) Human population growth and the demographic transition. Philos Trans R SocLond B BiolSci 364(1532):29852990

13. Delivorias A, Sabbati G (2015) EU demographic indicators: situation, trends and potential challenges. EPRS PE 551:335 
14. Wofford JL, Schwartz E, Timerding BL, Folmar S, Ellis SD, Messick CH (1996) Emergency department utilization by the elderly: analysis of the National Hospital Ambulatory Medical Care Survey. Acad Emerg Med 3:694-699

15. Huang JA, Weng RH, Tsai WC, Hu WH, Yang DY (2003) Analysis of emergency department utilization by elderly patients under National Health Insurance. Kaohsiung J Med Sci 19:113-119

16. Gardner RL, Almeida R, Maselli JH, Auerbach A (2010) Does gender influence emergency department management and outcomes in geriatric abdominal pain? J Emerg Med 39(3):275-281

17. Rosenthal RA, Andersen DK (1993) Surgery in the elderly: observations on the pathophysiology and treatment of cholelithiasis. Exp Gerontol 28(4-5):459-472

18. McSherry CK, Ferstenberg H, Calhoun WF (1985) The natural history of diagnosed gallstone disease in symptomatic and symptomatic patients. Ann Surg 202:59-63

19. Kenig J, Wałega P, Olszewska U, Konturek A, Nowak W (2016) Geriatric assessment as a qualification element for elective and emergency cholecystectomy in older patients. World J Emerg Surg 11(36):1-7

20. Spangler R, Van Pham T, Khoujah D, Martinez JP (2014) Abdominal emergencies in the geriatric patient. Int J Emerg Med $7: 43$

21. Omari AH, Khammash MR, Qasaimeh GR, Shammari AK, Yaseen MKB, Hammori SK (2014) Acute appendicitis in the elderly: risk factors for perforation. World J Emerg Surg 9(1):6
22. Ferzoco LB (1998) Acute diverticulitis [review]. N Engl J Med 338(21):1521-1526

23. Ragsdale L, Southerland L (2011) Acute abdominal pain in the older adult. Emerg Med Clin N Am 29:429-448

24. Ong M, Guang TY, Yang TK (2015) Impact of surgical delay on outcomes in elderly patients undergoing emergency surgery: a single center experience. World J Gastrointest Surg 7(9):208-213

25. Janssen-Heijnen M, Maas H, Houterman S, Lemmens VE, Rutten HJ, Coebergh JW (2007) Comorbidity in older surgical patients: influence on patient care and outcome. Eur J Cancer 43(15): 2179-2193

26. Al-Temimi MH, Griffee M, Enniss TM et al (2012) When is death inevitable after emergency laparotomy? Analysis of the American College of Surgeons National Surgical Quality Improvement Program database. J Am Coll Surg 215:503-511

27. Scarborough JE, Pappas TN, Bennett KM, Lagoo-Deenadayalan S (2012) Failure-to-pursue rescue: explaining excess mortality in elderly emergency general surgical patients with preexisting "do-notresuscitate" orders. Ann Surg 256:453-461

28. Soyalp C, Yuzkat N, Kilic M, Akyol ME, Demir CY, Gulhas N (2019) Operative and prognostic parameters associated with elective versus emergency surgery in a retrospective cohort of elderly patients. Aging Clin Exp Res 31(3):403-410

Publisher's Note Springer Nature remains neutral with regard to jurisdictional claims in published maps and institutional affiliations. 